\title{
Ocular melanoma is not associated with CDKN2A or MC1R variants - a population-based study C. Vajdic ${ }^{a}$, A. Kricker ${ }^{b}$, D.L. Duffy', J.F. Aitken ${ }^{d}$, M. Stark ${ }^{c}$, J.A.C. ter Huurne ${ }^{e}$, N.G. Martin ${ }^{\mathrm{c}}$, B.K. Armstrong ${ }^{f}$ and N.K. Hayward ${ }^{\mathrm{c}}$
}

\begin{abstract}
Germline variants in the melanocortin 1 receptor gene (MC1R) and the p16 gene (CDKN2A) are associated with an increased risk of cutaneous melanoma. The frequency of these germline variants was examined in a populationbased, incident series of 62 ocular melanoma cases and ethnicity-matched population controls. In both cases and controls, $59 \%$ of individuals carried at least one MC1R variant and there were no significant differences in the frequency of any of the five most common variants of $M C 1 R$. We also found no significant differences between cases and controls in the frequency of any of the four most common variants of $C D K N 2 A$, and no melanoma case carried a deleterious germline CDKN2A mutation. Our findings argue against an important predisposing effect of the MC1R and CDKN2A genes for ocular melanoma. Melanoma Res 13:409-413 @ 2003 Lippincott Williams \& Wilkins.
\end{abstract}

\section{Introduction}

Melanoma is the most common primary intra-ocular tumour in adults of mainly European origin; the incidence of microscopically verified ocular melanoma in these populations in 1988-1992 ranged up to 1.1 per 100000 in men and 1.0 per 100000 in women [1]. In hospital-based studies, few ocular melanoma cases $(<1 \%)$ reported a family history of ocular melanoma [2]; about $4 \%$ reported a family history of cutaneous melanoma [3].

Germline mutations of the breast cancer susceptibility gene BRCA2 have been reported in $2-3 \%$ of ocular melanoma cases [4-6], but no other ocular melanoma susceptibility genes have been identified. The search for candidate susceptibility genes has focused on those known to be associated with cutaneous melanoma, e.g. the cell cycle regulatory genes, $C D K N 2 A$ [7] and $C D K 4$ [8], and the melanocortin 1 receptor gene $(M C 1 R)$, a pigmentation-related gene $[9,10]$, but no associations of germline mutations in these genes with ocular melanoma have been reported $[8,11-15]$.

No population-based study of the relationship between ocular melanoma and CDKN2A and MC1R mutations has been reported. As ocular and cutaneous melanomas have been shown to share some phenotypic and environ-

\author{
Melanoma Research 2003, 13:409-413 \\ Keywords: CDKN2A, MC1R, ocular melanoma, polymorphisms \\ ${ }^{a}$ National Centre for HIV Epidemiology and Clinical Research, Darlinghurst, NSW \\ and The Cancer Council, NSW, Kings Cross, NSW, Australia, b ${ }^{\text {National Breast }}$ \\ Cancer Centre, Camperdown, NSW, Australia, ${ }^{\circ}$ Cancer and Cell Biology \\ Division, Queensland Institute of Medical Research, 300 Herston Rd, Herston, \\ Old 4029, Australia, dEpidemiology Unit, Queensland Cancer Fund, Spring Hill, \\ Qld, Australia, e Departments of Dermatology and Human Genetics, Leiden \\ University Medical Center, Leiden, The Netherlands, and f School of Public \\ Health, The University of Sydney, NSW and The Cancer Council NSW, Kings \\ Cross, NSW, Australia.
}

Sponsorship: This work was supported by the National Health and Medical Research Council of Australia, the National Institutes of Health (grant CA88363), the Cancer Council of New South Wales and the Barraba Cancer Patients Support Group.

Correspondence and requests for reprints to N.K. Hayward, Cancer and Cell Biology Division, Queensland Institute of Medical Research, 300 Herston Rd, Herston, Old 4029, Australia.

Tel: 61-7-33620306; fax:61-7-38453508; e-mail: nickH@qimr.edu.au

Received 22 August 2002

Accepted 5 February 2003

mental risk factors in population-based epidemiological studies $[16,17]$, it could be argued that the association between germline $M C 1 R$ and $C D K N 2 A$ variants and ocular melanoma risk ought to be examined in a population-based study. We aimed to do this in a sample of cases from our population-based study of ocular melanoma [16] and controls genotyped in recent studies of cutaneous melanoma $[7,9]$.

\section{Materials and methods Cases}

Patients with ocular melanoma were eligible for this study if they were diagnosed at 50 years of age or younger or had bilateral disease diagnosed at any age. These restrictions were applied to maximize the likelihood of finding germline mutations. A total of 107 eligible cases was ascertained for a population-based case-control study covering all cases of ocular melanoma diagnosed between 1 January 1996 and 31 July 1998 in Australia [16]. Ninety-nine (93\%) of these patients were interviewed for the study. Eighty $(81 \%)$ gave a blood sample, and sufficient DNA for analysis was extracted from 71. The homogeneity of ethnicity in cases and controls (see below) was considered to be important, and analyses for the present study were restricted to 62 cases with reported British or other northern European ethnicity (defined as having three or 
more grandparents born in England, Ireland, Scotland, Wales, Isle of Man, UK undefined, Austria, Belgium, Denmark, Finland, France, Germany, Netherlands, Norway, Sweden or Switzerland).

All cases had melanomas originating in the choroid, ciliary body, iris or conjunctiva and were included whether or not the diagnosis had been confirmed histopathologically. The distributions of primary tumour site, morphology, size and stage at diagnosis in these cases were similar to those of other cases in the larger population-based study, except for a relatively smaller proportion of conjunctival melanomas (Table 1). Most (84\%) originated in the choroid or ciliary body and $54 \%$ were histopathologically confirmed. One case had a first-degree relative with confirmed cutaneous melanoma and three others reported a family history of cutaneous melanoma that was not confirmed. None had a first-degree relative with confirmed ocular melanoma.

\section{Controls}

Controls were subjects sampled from the Australian National Health and Medical Research Council Twin Register and members of their families who had been used as controls in studies of cutaneous melanoma and $M C 1 R$ [9] and CDKN2A [7] mutations or polymorph-

Table 1 Distributions of tumour characteristics for study subjects with genetic analyses and the incident series from which they were drawn

\begin{tabular}{|c|c|c|c|c|}
\hline \multirow[b]{2}{*}{ Tumour characteristic } & \multicolumn{2}{|c|}{$\begin{array}{l}\text { Genetic study } \\
\text { subjects }\end{array}$} & \multicolumn{2}{|c|}{$\begin{array}{l}\text { Incident } \\
\text { cases }^{\mathrm{a}}\end{array}$} \\
\hline & $n$ & $\%$ & $n$ & $\%$ \\
\hline \multicolumn{5}{|l|}{ Ocular site of origin } \\
\hline Choroid or ciliary body & 52 & 83.9 & 102 & 79.1 \\
\hline Iris & 8 & 12.9 & 15 & 11.6 \\
\hline Conjunctiva & 2 & 3.2 & 12 & 9.3 \\
\hline Histopathologically verified & 33 & 53.2 & 76 & 58.9 \\
\hline \multicolumn{5}{|l|}{ Tumour morphology ${ }^{\mathrm{b}}$} \\
\hline Spindle & 18 & 54.5 & 34 & 44.7 \\
\hline Mixed & 10 & 30.3 & 25 & 32.9 \\
\hline Epithelioid & 3 & 9.1 & 7 & 9.2 \\
\hline Unspecified melanoma & 2 & 6.1 & 10 & 13.2 \\
\hline \multicolumn{5}{|l|}{ Tumour size $e^{\mathrm{c}, \mathrm{d}}$} \\
\hline Small & 17 & 32.7 & 27 & 26.5 \\
\hline Medium & 18 & 34.6 & 36 & 35.3 \\
\hline Large & 17 & 32.7 & 39 & 38.2 \\
\hline \multicolumn{5}{|l|}{ Tumour stage $\mathrm{c}^{\mathrm{C}}$} \\
\hline Localized to site of origin & 44 & 84.6 & 80 & 78.4 \\
\hline Spread to another ocular site ${ }^{\mathrm{e}}$ & 8 & 15.4 & 20 & 19.6 \\
\hline Unknown & 0 & 0.0 & 2 & 2.0 \\
\hline
\end{tabular}

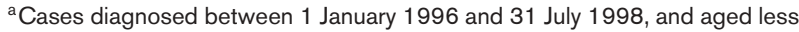
than or equal to 50 years at diagnosis or with bilateral ocular melanoma diagnosed at any age.

${ }^{b}$ Histopathologically verified cases only.

${ }^{\mathrm{C}}$ Choroid and ciliary body melanomas only.

dSmall, thickness $\leqslant 3.0 \mathrm{~mm}$ and diameter $<15.0 \mathrm{~mm}$; medium, $3.1 \mathrm{~mm} \leqslant$ thickness $\leqslant 8.0 \mathrm{~mm}$ and diameter $<15.0 \mathrm{~mm}$; large, thickness $>8.0 \mathrm{~mm}$, any diameter or diameter $\geqslant 15.0 \mathrm{~mm}$, any thickness.

${ }^{\mathrm{e} N o t}$ including sclera and optic nerve. isms. They included a sample of 200 unrelated individuals drawn from 3300 Register participants [7] and 738 individuals who were parents of twins in a study of naevus counts, including 218 who had been controls in a study of $M C 1 R$ polymorphisms and melanoma risk [9]. The total pool of 938 controls was restricted for these analyses to 738 individuals with self-reported British or other northern European ancestry as defined for the cases above; no age restrictions were applied. All 738 selected controls had been genotyped for five common MC1R variants, and four common CDKN2A polymorphisms had been sought in 131 .

\section{Data collection}

Cases reported their ethnicity in a telephone interview [16], whereas controls supplied their ancestry in a mailed, self-administered questionnaire [7,9].

\section{DNA extraction}

DNA was extracted using a modified 'salting out' procedure as described previously [7].

\section{MC1R genotyping \\ Cases}

To obtain sufficient DNA for sequencing of the entire $M C 1 R$ gene, a nested primer polymerase chain reaction (PCR) strategy was used, as described previously [18], for the amplification of extracted genomic DNA from each subject. The first primer set, hMC1R N-outer and C-outer [18], was used in a $25 \mu \mathrm{l} \mathrm{PCR}$ containing $25 \mathrm{ng}$ of genomic DNA, $1 \times$ PCR buffer containing $20 \mathrm{mM}$ Tris-HCl and $50 \mathrm{~mm} \mathrm{KCl} \mathrm{(Promega,} \mathrm{Madison,} \mathrm{WI,}$ USA), $10 \%$ dimethyl sulphoxide (DMSO), $1.5 \mathrm{mM}$ $\mathrm{MgCl}_{2}$, 25 pmol of each primer, $200 \mu \mathrm{M}$ of each deoxynucleotide triphosphates (dNTP) and $1.25 \mathrm{U}$ of Taq DNA polymerase (Promega). Cycle conditions were: initial denaturation for $3 \mathrm{~min}$ at $94^{\circ} \mathrm{C}$, followed by 34 cycles of $1 \mathrm{~min}$ at $94^{\circ} \mathrm{C}, 1 \mathrm{~min}$ at $55^{\circ} \mathrm{C}$ and $2 \mathrm{~min}$ at $72^{\circ} \mathrm{C}$, concluding with a 7 min extension at $72^{\circ} \mathrm{C} ; 5 \mu \mathrm{l}$ of the first-round reaction was used as a template to seed a second $25 \mu \mathrm{l}$ reaction that used $25 \mathrm{pmol}$ of the $\mathrm{N}$-inner and C-inner primer pairs [18]. The amplification conditions were identical to the first round and the products were used for direct sequencing of the MC1R coding region $[9,18]$. Sequencing was performed by the addition of 100-200 ng of DNA template to $8 \mu \mathrm{l}$ of Applied Biosystems Incorporated (ABI) Prism dye terminator premix (utilizing AmpliTaq DNA Polymerase FS [Perkin Elmer]) and 3.2 pmol primer. Reactions were made up to $20 \mu \mathrm{l}$ with MilliQ water and covered with paraffin oil. Three sequencing primers were utilized per template - the $\mathrm{N}$-inner and $\mathrm{C}$-inner primers, as well as an internal (Seq3) primer [18]. Cycling was carried out using: $30 \mathrm{~s}$ at $96^{\circ} \mathrm{C}, 15 \mathrm{~s}$ at $50^{\circ} \mathrm{C}$ and $4 \mathrm{~min}$ at $60^{\circ} \mathrm{C}$ for 25 cycles. PCR reaction products were ethanol precipitated, dried for $1 \mathrm{~min}$ at $95^{\circ} \mathrm{C}$ and submitted to an ABI 373 automated sequencer. Se- 
quence data were analysed utilizing the program Sequencher (Genecodes).

\section{Controls}

Adult twins $(n=200)$ were genotyped at V60L, D84E, R151C, R160W and D294H, whilst the parents of adolescent twins $(n=738)$ were genotyped at V60L, D84E, V92M, R151C, I155T, R160W, R163Q, D294H and $\mathrm{R} 142 \mathrm{H}$, as described previously [9,18]. Only variants common to the two sources of controls were included in the analyses.

\section{CDKN2A genotyping}

CDKN2A was amplified as described previously $[19,20]$. Briefly, the promoter region was amplified using primers $96 \mathrm{~F}$ and $968 \mathrm{R}$, the $5^{\prime}$ untranslated region (UTR) and exon 1 were amplified using primers $781 \mathrm{~F}$ and $1424 \mathrm{R}$, exon 2 was amplified with primers $42 \mathrm{~F}$ and $551 \mathrm{R}$, and exon 3 was amplified with primers $\mathrm{X} 3 \mathrm{P} 2 \mathrm{~F}$ and X3P2R [20]. All PCRs involved a 'touchdown' thermal cycling routine of two cycles at each annealing temperature, decreasing by $2^{\circ} \mathrm{C}$, followed by 25 cycles at the lower temperature. Each cycle consisted of $45 \mathrm{~s}$ at $94^{\circ} \mathrm{C}, 90 \mathrm{~s}$ at the annealing temperature and $90 \mathrm{~s}$ at $72^{\circ} \mathrm{C}$. A $12 \mathrm{~min}$ initial denaturing step at $94^{\circ} \mathrm{C}$ and a 3 min final extension step at $72^{\circ} \mathrm{C}$ were also employed. PCR reactions consisted of 100-200 ng DNA, 10-30 pmol of each primer and $200 \mathrm{nM}$ dNTPs (Promega) and were performed with 1.25 U of Amplitaq Gold (Hoffman-La Roche, Basel, Switzerland) in $100 \mathrm{~mm}$ Tris$\mathrm{HCl}, \mathrm{pH} 8.3,500 \mathrm{mM} \mathrm{KCl}$ and $1.5 \mathrm{mM} \mathrm{MgCl}_{2}$. Due to the high $\mathrm{GC}$ content of the $C D K N 2 A$ gene, reactions were performed in a final concentration of $500 \mathrm{mM}$ betaine (Sigma Chemical Company, St Louis, MO, USA). All products were electrophoresed on a $1.5 \%$ TAE agarose gel, excised and purified using a QIAquick Gel Extraction Kit (Qiagen, Hilden, Germany).
The fragments were sequenced with the same primers as used for the PCR step, and the 5'UTR was additionally sequenced with primer 427F [20] using ABI dye terminator sequencing kits according to the manufacturer's specifications. Sequencing products were run on an ABI 377 automated sequencer (PE Applied Biosystems, Foster City, CA, USA). The whole of the $C D K N 2 A$ coding region was screened for mutations in cases, whilst four common CDKN2A polymorphisms were assessed in control subjects.

\section{Statistical analysis}

We compared gene variant frequencies in cases and controls using the chi-squared test; $P<0.05$ was considered to be significant. Standard multivariate logistic regression analyses were performed using the $\mathrm{R}$ statistics package [21]. These analyses included models containing age and sex, as well as a full model that included age, sex and genotype for the five 'red hair colour' $M C 1 R$ and the four CDKN2A polymorphisms. Linkage disequilibrium (association) between the different variants was automatically adjusted for in the multiple regression framework. When multiple variants are included as predictors in the logistic framework, this appears in the correlation matrix for the predictor variables and so is conditioned on.

\section{Results \\ Frequency of $M C 1 R$ variants}

Identical proportions (59\%) of cases and controls had at least one $M C 1 R$ variant. There were no significant differences between cases and controls in the frequency of any of the five most common variants of $M C 1 R$ (Table 2). There was also no significant association with ocular melanoma when all variant alleles were pooled (Table 3).

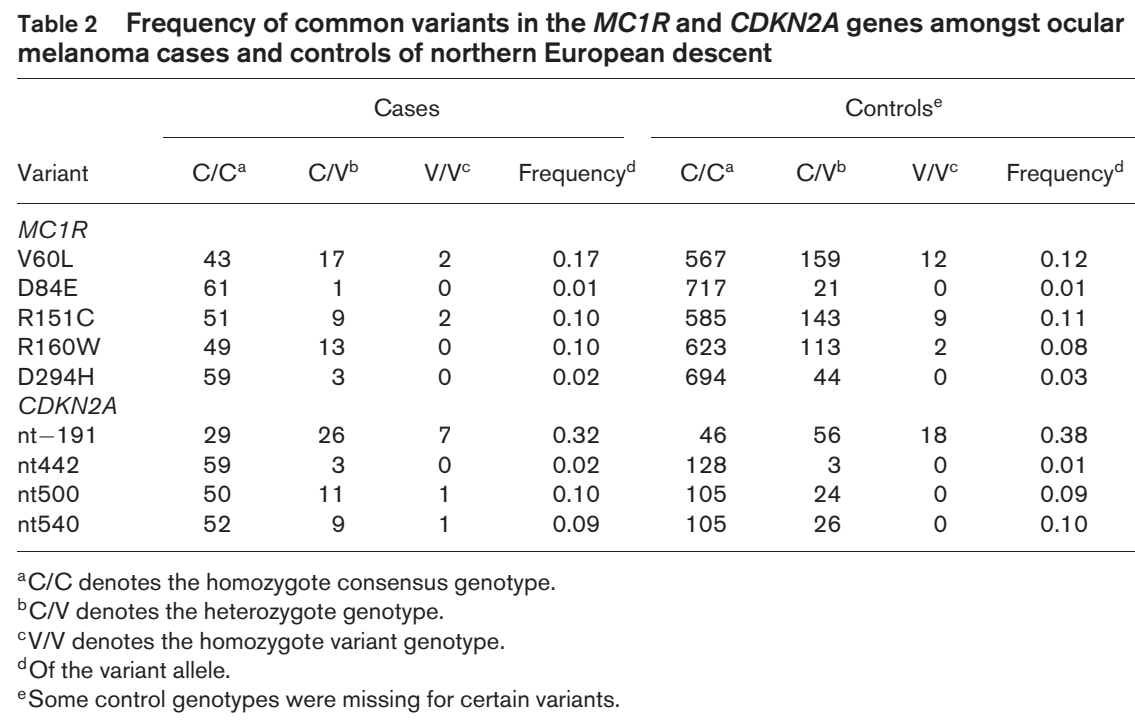




\section{CDKN2A genotype}

We found no significant differences between cases and controls in the frequency of any of the four most common variants of CDKN2A (Table 2), and none of these polymorphisms was associated with an increased risk of ocular melanoma (Table 4). No case of ocular melanoma carried a deleterious germline CDKN2A mutation.

\section{Discussion}

In our series of young, non-familial, ocular melanoma cases in a population-based case-control study, we found no deleterious mutations of CDKN2A and no evidence of associations between ocular melanoma and a number of polymorphisms in CDKN2A and MC1R.

Deleterious germline mutations of CDKN2A have also not been found in previous studies of familial [11,12, $14]$ and sporadic $[8,13]$ ocular melanoma cases and ocular melanoma cases with a family history of cutaneous melanoma [11,14]. There is, however, some evidence that a loss of CDKN2A function may play a role in ocular melanoma. Although no evidence has been found of somatic mutation of CDKN2A in this disease [8,22], homozygous deletion of the gene or inactivation of it through hypermethylation of its pro-

Table 3 Relationship between the risk of ocular melanoma and MC1R genotype in 62 ocular melanoma cases and 726 controls of northern European descent

\begin{tabular}{lccc}
\hline & $\begin{array}{c}\text { Unadjusted odds } \\
\text { ratio }^{\mathrm{a}}\end{array}$ & $\begin{array}{c}\text { Adjusted odds } \\
\text { ratio }^{\mathrm{b}}\end{array}$ & $\begin{array}{c}95 \% \text { confidence } \\
\text { interval }\end{array}$ \\
\hline MC1R variants & & & \\
V60L & 1.47 & 1.47 & $0.85-2.45$ \\
D84E & 0.59 & 0.44 & $0.02-2.43$ \\
R151C & 0.97 & 0.67 & $0.33-1.28$ \\
R160W & 1.34 & 1.09 & $0.52-2.14$ \\
D294H & 0.89 & 0.87 & $0.19-2.71$ \\
Any variant & 1.08 & 1.05 & $0.69-1.59$ \\
\hline
\end{tabular}

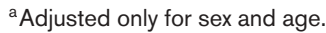

${ }^{\mathrm{b}}$ Adjusted odds ratios are from the logistic regression model including age, sex and the five $M C 1 R$ genotypes coded as 0 (no variant at that site), 1

(heterozygote) or 2 (homozygote). The exception is the case of 'any variant', where a single dummy variable replaced the five individual variants.

Table 4 Relationship between the risk of ocular melanoma and CDKN2A genotype in 62 ocular melanoma cases and 131 controls of northern European descent

\begin{tabular}{lccc}
\hline CDKN2A variants & $\begin{array}{c}\text { Unadjusted odds } \\
\text { ratio }^{\mathrm{a}}\end{array}$ & $\begin{array}{c}\text { Adjusted odds } \\
\text { ratio }^{\mathrm{b}}\end{array}$ & $\begin{array}{c}95 \% \text { confidence } \\
\text { interval }\end{array}$ \\
\hline $\mathrm{nt}-191$ & 1.04 & 0.80 & $0.40-1.55$ \\
$\mathrm{nt442}$ & 2.19 & 3.38 & $0.43-26.73$ \\
$\mathrm{nt500}$ & 1.03 & 0.86 & $0.35-2.08$ \\
$\mathrm{nt540}$ & 0.92 & 0.86 & $0.37-2.00$ \\
\hline
\end{tabular}

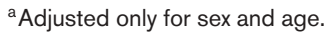

${ }^{\mathrm{b}}$ Adjusted for sex, age and $C D K N 2 A$ variant. Because there is linkage

disequilibrium between the different $C D K N 2 A$ polymorphisms, we have included

them as potential confounders. moter has been found in some cases [22,23]. Thus, the possibility of a role for the loss of $C D K N 2 A$ function in ocular melanoma remains open.

Our finding that $M C 1 R$ polymorphisms that increase the risk of cutaneous melanoma were not associated with the risk of ocular melanoma was similar to that of the only other study to examine this relationship in ocular melanoma [15]. These findings are compatible with the observation that red hair is not consistently associated independently with ocular melanoma [16]. Red hair is a known risk factor for cutaneous melanoma and the 'red hair colour' variant alleles of $M C 1 R$ (R151C, R160W and D294H) have been associated with an approximately two-fold increased risk $[9,10]$.

A similarity between the genetic determinants of ocular and cutaneous melanoma would not necessarily be expected. Although the melanocytes of the uvea, conjunctiva and skin have a common embryologic origin [24], there are important differences between them. Unlike cutaneous melanocytes, there is no evidence that incident ultraviolet radiation initiates melanogenesis in ocular melanocytes [25]. It is also uncertain whether uveal melanocytes produce melanin in vivo during adulthood [26]; ocular melanosomes are relatively inactive and remain within the melanocyte, whereas epidermal melanocytes continuously synthesize melanosomes and transfer them to keratinocytes [27]. Finally, the occurrence of ocular albinism, characterized by depigmentation of the eye but not the skin, suggests different melanogenesis pathways in ocular and cutaneous melanocytes [26]. To the contrary, however, recent evidence indicates that ocular melanocytes express melanocortin 1 receptors $(M C 1 R)$ on their surface and are responsive to $\alpha$-melanocytestimulating hormone, the agonist for these receptors [28].

In the absence of evidence of any important involvement of $C D K N 2 A$ and $M C 1 R$ in the causation of ocular melanoma, future work on susceptibility to ocular melanoma should focus on other genes, such as BRCA2 and genes that are functionally related to it.

\section{Acknowledgements}

Jeanette ter Huurne was the recipient of a travel fellowship from the Haak Bastiaanse-Kuneman Foundation, Vrije Universiteit Amsterdam and the Foundation of the Vrijvrouwe van Renswoude te'sGravenhage, The Netherlands. We thank Dr Louise O'Gorman and Ms Sue Boudry for their contribution to blood collection and processing, Associate Professor Rick Sturm for granting the use of MC1R genotypes previously ascertained in the controls, and Dr Michael Giblin and Dr John McKenzie for their clinical expertise. We are grateful to those who participated in the 
research and the ophthalmologists who notified their patients about the incidence survey and gave permission for us to approach them about the study.

\section{References}

1 Parkin DM, Whelan SL, Ferlay J, Raymond L, Young J. Cancer incidence in five continents. Vol. VII. International Agency for Research on Cancer (IARC) Scientific Publication 143. Lyon: IARC; 1997.

2 Singh AD, Wang MX, Donoso LA, Shields CL, De Potter P, Shields JA. Genetic aspects of uveal melanoma: a brief review. Semin Oncol 1996; 23:768-772.

3 Van Hees CL, Jager MJ, Bleeker JC, Kemme H, Bergman W. Occurrence of cutaneous and uveal melanoma in patients with uveal melanoma and their first degree relatives. Melanoma Res 1998; 8:175-180.

4 Easton DF, Steele L, Fields P, Ormiston W, Averill D, Daly PA, et al. Cancer risks in two large breast cancer families linked to BRCA2 on chromosome 13q12-13. Am J Hum Genet 1997; 61:120-128.

5 Sinilnikova OM, Egan KM, Quinn JL, Boutrand L, Lenoir GM, StoppaLyonnet $\mathrm{D}$, et al. Germline brca2 sequence variants in patients with ocular melanoma. Int J Cancer 1999; 82:325-328.

6 Iscovich J, Abdulrosik M, Cour C, Fischbein A, Pe'er J, Goldgar D. Prevalence of the BRCA2 6174delT mutation in Israeli uveal melanoma patients. Int J Cancer 2002; 98:42-44.

7 Aitken J, Welch J, Duffy D, Milligan A, Green A, Martin N, et al. CDKN2A variants in a population-based sample of Queensland families with melanoma. J Natl Cancer Inst 1999; 91:446-452.

8 Ohta M, Nagai H, Shimizu M, Rasio D, Berd D, Mastrangelo M, et al. Rarity of somatic and germline mutations of the cyclin-dependent kinase 4 inhibitor gene, CDK4I, in melanoma. Cancer Res 1994; 54: 5269-5272.

9 Palmer JS, Duffy DL, Box NF, Aitken JF, O'Gorman LE, Green AC, et al. Melanocortin-1 receptor polymorphisms and risk of melanoma: is the association explained solely by pigmentation phenotype? Am J Hum Genet 2000; 66:176-186.

10 Kennedy C, ter Huurne J, Berkhout M, Gruis N, Bastiaens M, Bergman $\mathrm{W}$, et al. Melanocortin 1 receptor (MC1R) gene variants are associated with an increased risk for cutaneous melanoma which is largely independent of skin type and hair color. J Invest Dermatol 2001; 117:294-300.

11 Wang X, Egan KM, Gragoudas ES, Kelsey KT. Constitutional alterations in p16 in patients with uveal melanoma. Melanoma Res 1996; 6: 405-410.

12 Singh AD, Croce CM, Wary KK, Shields JA, Donoso LA, Shields CL, et al. Familial uveal melanoma: absence of germline mutations involving the cyclin-dependent kinase-4 inhibitor gene ( $p 16)$. Ophthalmic Genet 1996; 17:39-40.

13 Blasi MA, Binni F, De Bernardo C, Grammatico B, Balestrazzi E, Grammatico P. Analysis of CDKN2A constitutional mutations in 15 patients affected by uveal melanoma. Invest Ophthalmol Vis Sci 2000; 41:S382.

14 Soufir N, Bressac-de Paillerets B, Desjardins L, Levy C, Bombled J, Gorin I, et al. Individuals with presumably hereditary uveal melanoma do not harbour germline mutations in the coding regions of either the P16 ${ }^{\text {INK4A }}$, P14 ${ }^{\text {ARF }}$ or cdk4 genes. Br J Cancer 2000; 82:818-822.

15 Metzelaar-Blok JA, ter Huurne JA, Hurks HM, Keunen JE, Jager MJ, Gruis NA. Characterization of melanocortin-1 receptor gene variants in uveal melanoma patients. Invest Ophthalmol Vis Sci 2001; 42:1951-1954.

16 Vajdic CM, Kricker A, Giblin M, McKenzie J, Aitken J, Giles GG, et al. Eye color and cutaneous nevi predict risk of ocular melanoma in Australia. Int J Cancer 2001; 92:906-912.

17 Vajdic CM, Kricker A, Giblin M, McKenzie J, Aitken J, Giles GG, et al. Sun exposure predicts risk of ocular melanoma in Australia. Int J Cancer 2002; 101:175-182.

18 Box NF, Wyeth JR, O'Gorman LE, Martin NG, Sturm RA. Characterization of melanocyte stimulating hormone variant alleles in twins with red hair. Hum Mol Genet 1997; 6:367-376.

19 Castellano M, Pollock PM, Walters MK, Sparrow LE, Down LM, Gabrielli $\mathrm{BG}$, et al. CDKN2A/p16 is inactivated in most melanoma cell lines. Cancer Res 1997; 57:4868-4875.

20 Pollock PM, Stark MS, Palmer JM, Walters MK, Aitken JF, Martin NG, et al. Mutation analysis of the CDKN2A promoter in Australian melanoma families. Genes Chromosom Cancer 2001; 32:89-94.

21 Ihaka R, Gentleman R. R: A language for data analysis and graphics. J Computational Graph Stat 1996; 5:299-314.

22 Merbs SL, Sidransky D. Analysis of p16 (CDKN2/MTS-1/INK4A) alterations in primary sporadic uveal melanoma. Invest Ophthalmol Vis Sci $1999 ; 40: 779-783$.
23 van der Velden PA, Metzelaar-Blok JA, Bergman W, Monique $\mathrm{H}$, Hurks $\mathrm{H}$, Frants RR, et al. Promoter hypermethylation: a common cause of reduced p16(INK4a) expression in uveal melanoma. Cancer Res $2001 ; 61$ : 5303-5306.

24 Sarna T. Properties and function of the ocular melanin-a photobiophysical view. J Photochem Photobiol 1992; 12:215-258.

25 Sahm M, Loeffler KU, Seifert P, Spitznas M. Effect of ultraviolet radiation on melanogenesis in four different types of cultured bovine ocular pigmented cells. Graefe's Arch Clin Exp Ophthalmol 2001; 239: 302-309.

26 Hu DN, McCormick SA, Orlow SJ, Rosenblat S, Lin AY. Regulation of melanogenesis by human uveal melanocytes in vitro. Exp Eye Res 1997; 64:397-404.

27 Boissy RE. The melanocyte. Its structure, function, and subpopulations in skin, eyes, and hair. Dermatol Clin 1988; 6:161-173.

28 Smith-Thomas LC, Moustafa M, Dawson RA, Wagner M, Balafa C, Haycock JW, et al. Cellular and hormonal regulation of pigmentation in human ocular melanocytes. Pigment Cell Res 2001; 14:298-309. 